\title{
Work Alienation as a Mediator of the Relationship between Organizational Injustice and Organizational Commitment: Implications for Healthcare Professionals
}

\author{
Seyfettin Sulu (Corresponding author) \\ Department of Business Administration, Gebze Institute of High Technology (Gyte) \\ Camcesme Mah. Gunes Sok. No:2, PO Box 34899, Pendik, Istanbul, Turkey \\ Tel: 9-0506-606-6692Ｅ-mail: seyfettinsulu@hotmail.com \\ Adnan Ceylan (Assoc. Prof.) \\ Department of Business Administration, Gebze Institute of High Technology (Gyte) \\ PO Box 41400, Istanbul Cad., Gebze Kocaeli, Turkey \\ Tel: 9-0532-235-3956_E-mail: aceylan@gyte.edu.tr \\ Ramazan Kaynak (Assoc. Prof) \\ Department of Business Administration, Gebze Institute of High Technology (Gyte) \\ PO Box 41400, Istanbul Cad., Gebze Kocaeli, Turkey \\ E-mail:kaynak@gyte.edu.tr
}

\begin{abstract}
Organizational justice is an important predictor of several job attitudes and behaviors such as trust, turnover intention, job satisfaction, job stress, organizational commitment, sabotage in workplace. This study examines the relationship between two dimensions of organizational injustice and organizational commitment, and whether work alienation has mediating effects in this relationship. It was hypothesized that distributive and procedural injustice would cause organizational commitment, and dimensions of work alienation would serve as mediators in this relationship. These relationships were tested in a sample of 383 healthcare professionals (nurses and physicians) from public and private hospitals in Istanbul. The results revealed that both distributive injustice and procedural injustice were associated with organizational commitment, and each of the work alienation dimensions partially mediated this relationship. The theoretical and practical implications of this results were discussed below.
\end{abstract}

Keywords: Organizational injustice, Powerlessness, Social 1solation, Work alienation, Organizational commitment

\section{Introduction}

In many studies, it has been suggested that fairness affects several employee attitudes and behaviors such as job satisfaction, organizational commitment, sabotage, turnover intention, stress, organizational citizenship behavior, job performance, and trust (Folger \& Konovsky, 1989; Byrne, 2005; Lambert, Hogan, \& Griffin, 2007; Robbins, Summers, \& Miller, 2000; Dailey \& Kirk, 1992; Boer et al., 2002; Greenberg, 2004; Colquitt et al., 2001; Hubbel \& Chory-Assad, 2005; Ambrose, Seabright, \& Schminke, 2002; Vermunt \& Steensma, 2003; Judge \& Colquitt, 2004). Research on work alienation has also focused on its nature and predicting the antedecents and consequences of it such as isolation in organizations, organizational leadership, organizational citizenship behavior, organizational commitment, drinking behavior, and satisfaction (Miller, 1975; Sarros et al., 2002; Banai \& Reisel, 2007; Mendoza \& Lara, 2007; Banai, Reisel, \& Probst, 2004; Yang, Yang, \& Kawachi, 2001; Bacharach \& Aiken, 1979).

In recent years, healthcare industry has become a focus of research, especially in the context of hospital-based care. Among the healthcare professionals nurses appear to be the most discussed group in organizational justice 
literature (Brooks \& Zeitz, 1999; Posthuma, Maertz, \& Dworkin, 2007; VanYperen et al., 2000; Greenberg, 2006; Leiter \& Maslach, 2009; Tallman, Phipps, \& Matheson, 2009). This study takes into account the perceived organizational injustice (distributive and procedural injustice) of healthcare professionals, and examines whether they have effects on organizational commitment. Furthermore, it is examined whether work alienation dimensions, which has not referred previously in organizational justice literature, have mediating effects on this relationship. Healthcare professionals were chosen for this study. Because, healthcare is one of the most important, and rapidly growing industry in Turkey in recent years, and with this rapid growth several complaints especially related with work outcomes (pay, bonus etc.) have began to arise among healthcare professionals. Loosing this technical skilled employees may costly and impede the effective functioning of an hospital. In this respect, it is important to provide their commitment to the hospital for the successful operation of healthcare services. Organizational justice may increase an employee's loyalty to the organization.

\section{Literature review}

\subsection{Organizational injustice}

Organizational justice means the extent to which employees are treated justly (Elovainio et al., 2005) and whether the outcomes obtained and the processes carried out are fair at workplace (Hubbel \& Chory-Assad, 2005). Early organizational justice literature distinguished between three types of justice as distributive, procedural and interactional justice (Greenberg, 1990; Konovsky, 2000; Folger \& Konovsky, 1989). Later, it was proposed that interactional justice has two subcategories, namely informational justice and interpersonal justice, and these subcategories should be considered separately (Colquitt, 2001; Colquitt et al., 2001).

Distributive justice is the first justice construct and means the perceived fairness of decision outcomes such as monetary rewards employees receive in an exchange relationship with the organization (Elovainio et al., 2004; Folger \& Konovsky, 1989; Colquitt et al., 2006; Greenberg, 2006; Ramamoorthy \& Flood, 2004; Aryee, Budhwar, \& Chen, 2002). In the case of something valuable is scarce, everyone can not have what she or he wants, or a negative situation can not be avoided by all, perceptions of distributive injustice may occur. Distributive justice is judged by evaluating and comparing the outcome to a standard or rule and/or to the outcome by a referent, such as a co-worker or past experience (Hubbel \& Chory-Assad, 2005). Employees create justice perceptions by gauging whether outcomes are proportional to their inputs, whether outcomes meet their expectations, and comparing their input/outcome ratio to those of their counterparts (Alder \& Ambrose, 2005; Colquitt et al., 2006; Greenberg, 2006). For example, an employee will perceive a monetary reward such as pay raise or bonus as unfair if he or she receives less money than another employee who is perceived to work at the same level (Greenberg, 1990). Resource allocation is important for physicians to be able to deliver healthcare services and accomplish their goals. Although physicians do not determine how and where resources are allocated, they may be able to influence distribution of resources through participation in decision making processes (Tallman, Phipps, \& Matheson, 2009).

Procedural justice means most generally that how an allocation decision is made (Ding \& Lin, 2006). It is the perceived fairness of procedures which are the means used to make or implement decisions and determine the outcomes (DeConinck \& Bachmann, 2005; Byrne, 2005; Ding \& Lin, 2006; Elovainio et al., 2004; Folger \& Konovsky, 1989; Greenberg, 2001; Greenberg, 2004; Aryee, Budhwar, \& Chen, 2002). Control model of justice proposes that procedural justice provides employees with indirect influence over the outcome of the decision-making process by means of process control. Process control which has also been called voice in justice literature, refers an employee's possibility to express his/her view during the decision-making process (Hegtvedt, Clay-Warner, \& Johnson, 2003). Decision-making procedures allowing voice help employees to control and influence material outcomes (Ding \& Lin, 2006; Price et al., 2006). Such control can produce more favorable outcomes (DeConinck \& Bachmann, 2005). According to Leiter and Maslach (2009) control is associated with fairness and reward, and helps nurses to work according to their values and to develop a healthy, sustaining worklife. Before a decision is made concerns of all affected subgroups and individuals should be considered carefully (Greenberg \& Barling, 1999; Schmitt \& Dörfel, 1999). Allocation processes and procedures should be representative of all affected employees' views, opinions, needs, and values in the process (Judge \& Colquitt, 2004; Cohen-Charash \& Spector, 2001). The information used in a decision by management should fairly represent the views of all affected employees (Posthuma, Maertz, \& Dworkin, 2007). Another explanation is offered in group-value model that voice increases feelings of inclusion, respect, and standing within a group (Price et al., 2006). An unfair procedure indicates that individual is a low status member within the group or the relationship between group member and the authority figure is negative (Cropanzano et al., 2001). 


\subsection{Organizational commitment}

Organizational commitment is a state in which an employee feels loyalty to the organization, accept and internalize goals and values of it, and involves in the organization (Lambert, Hogan, \& Griffin, 2007; Fang, 2001). Even when committed employees faced with attractive alternatives they prefer to maintain the employment relationship with the organization they work (Fang, 2001). Organizational commitment is an affective or emotional attachment to the organization as a whole (Allen \& Meyer, 1990; Martin \& Bennett, 1996; Brooks \& Zeitz, 1999).

Fairness provides employees opportunity to control, esteem and sense of belonging which are critical predictors of organizational commitment. Procedural justice provides employees to believe that organizational and managerial decisions are legitimate. Beliefs of legitimacy provides employees commitment to the organization (Tallman, Phipps, \& Matheson, 2009). Employees who believe that they are treated fairly will be likely to hold positive attitutes toward the organization, outcomes, and supervisors, and be more committed to the organization. Both distributive and procedural justice were reciprocally related with organizational commitment (Robbins, Summers, \& Miller, 2000). According to Aryee, Budhwar, and Chen (2002) distributive justice and procedural justice both directly and indirectly (through trust in organization) related with organizational commitment. In Martin and Bennett's (1996) study it was found that procedural justice, rather than distributive justice, determined organizational commitment. In a meta-analytic review of the existing organizational justice literature, Colquitt et al. (2001) stated that procedural and distributive justice influenced an employee's commitment to the organization. According to Sweeney and McFarlin (1997) both procedural and distributive justice were associated with higher commitment. In a study of 507 hospital nurses, Brooks and Zeitz (1999) found that Total Quality Management dimensions related with perceptions of procedural justice, and such perceptions mediated the effects of TQM on affective commitment.

Most of the organizational commitment measures are based on affective commitment. Affective commitment is an employee's identification with the organization and its goals, and desire to maintain membership in the organization. Both the procedural and distributive justice perceptions were related with affective commitment. The higher the perceived distributive justice and procedural justice of employees, the higher their commitment to the organization (Ramamoorthy \& Flood, 2004). Lambert, Hogan, and Griffin (2007) stated that distributive and procedural justice had significant effects on correctional staff organizational commitment. Cohen-Charash and Spector (2001) also found that both distributive justice and procedural justice were equally and positively related with affective commitment.

\subsection{Work alienation as a mediator}

Alienation at the workplace refers that employees may not be able to fulfill their social needs (Nasurdin, Ramayah, \& Kumaresan, 2005) and they have a form of gap between perceptions of an objective work situation and their certain interests such as values, ideals, and desires (Mendoza \& Lara, 2007). Work alienation cognitively separates an employee from work and the workplace and manifests itself in the form of decreased job involvement and a lack of organizational identification (Armstrong-Stassen, 2006). It containes work characteristics such as limited decision making and minimal skill usage (Berger et al., 2008). An alienated person has a lack of involvement in the work role and disengages from the work. Work alienation was previously a component of a commitment propensity (Hirschfeld \& Feild, 2000; Banai \& Reisel, 2007).

As a result of the absence of autonomy and control in the workplace, workers may experience alienation (Kanungo, 1983). Alienation decreases the motivation of workers, psychologically separates them from work and acts to reduce work involvement. Alienated workers are inability to satisfy their salient needs and expectations from work (Banai, Reisel, \& Probst, 2004). One of the three indicators of alienation is lack of commitment to organizational goals. Employees who alienated from work view their jobs instrumentally, avoid autonomy, responsibility, and higher status, and engage in nonwork pursuits. They do not care personally participation in work processes and are not personally involve in work, their goal is to earn money (Shepard, 1970).

When a person is treated exclusive, differently or unfairly because of his or her group membership he or she often feels alienated and angry (Enshner, Grant-Vallone, \& Donaldson, 2001). According to Allen and LaFollette (1977) organizations in which there was a lack of autonomy for the employee in the selection of tasks and not allowed enough to participate in decision making were likely to cause high degree of work alienation. There was an inverse relationship between alienation from work and participation in decision making. In the case of low participation in decision making, trainees from a Management training program experienced work alienation. Two dimensions of work alienation (powerlessness and social isolation) were discussed in this study. 
Powerlessness is the absence of control over events in a person's life (Banai \& Reisel, 2007) and an employee's inability to control work process at the workplace (Yang, Yang, \& Kawachi, 2001; Bacharach \& Aiken, 1979). Alienated workers perceive that control is lacking over the pace and method of the work and over his or her physical movements (Leiter, 1985). In an alienated work environment, workers neither control the work process nor do they participate in organizational decision-making. Generally, powerlessness may have two sub-dimensions, whether the workers are free of action in the work process, and have influence on organizational decision-making (Bacharach \& Aiken, 1979).

Powerlessness means that one has no influence on decisions. Nursing discourse was subordinated to managerial discourse, and nurses were relatively powerless in relation to managers. Behavior of managers had the influence on powerlessness (Taylor, White, \& Muncer, 1999). Medical management mostly controls the distribution of resources. If physicians have not the decision making power for resource allocation, they will feel there is an injustice in the distribution of resources and in the decision making processes, and will not accomplish their goals efficiently. Consequently they may move to find another solution (Tallman, Phipps, \& Matheson, 2009). According to Tabak and Koprak (2007) nurses tend to avoid from feelings of powerlessness because powerlessness prevent them to solve a problem. Status and power help nurses to resolve or ignore conflicts with doctors.

Many studies have emphasized the negative consequences of feelings of powerlessness. According to Zellars et al. (2004) low procedural justice may cause employees to perceive little or no control, and these sense of powerlessness prevent him/her to take action against the source of stress. Lack of freedom or autonomy leads to powerlessness, and individuals who has a sense of powerlessness may engage in destructive behaviors such as sabotage to regain control (Ambrose, Seabright, \& Schminke, 2002). As Greenberg and Barling (1999) stated job insecurity reflects the perceived powerlessness to keep control over one's job, and is likely to result in anxiety and stress, intent to leave, and decreased job satisfaction, commitment, and trust in company. Another negative consequence of feelings of powerlessness is the reduction in organizational commitment. When employees are allowed to participate in goal-setting they accept this goal and their commitment to the organization increases (Kanungo, 1992). Employees who can influence their work environment may experience greater attachment to their organizations. Powerlessness and organizational commitment are significantly and negatively associated. To provide employees to access resources and determine their roles increases sense of power. Equitable distribution of resources and job autonomy are likely to enhance an individual's sense of power (Gilbert \& Ivanchevich, 1999).

A socially isolated employee is not supported or helped by his or her colleagues or superiors (Yang, Yang, \& Kawachi, 2001). Employees have not enough inclusion and socially acceptance at workplace (Banai \& Reisel, 2007) and perceive that they have a lack of integration with their coworkers, their occupation, or the organization they work (Leiter, 1985). Organizations do not equally distribute personal influence or organizational power, and do not generate equally flexible or identically rewarding interaction patterns among their members. The amount of freedom workers have to socially interact with other members affect their ability to influence the group's functioning (Miller, 1975).

Workplace isolation is a psychological construct which defines perceived isolation of employees' from the organization and coworkers. Workplace isolation has two dimensions, namely company isolation and colleague isolation. Company isolation refers how much supervisor and the organization support employees and how well employees' contributions are taken into consideration by the company. On the other hand, colleague isolation means how isolated an employee feels from colleagues and other workers. There was a relationship between company isolation and organizational commitment (Mulki et al., 2008).

Commitment increases an employee's desire to work, and leads to work efficiently. However, work alienation separates his/her from work environment and social interactions at work. For this reason, work alienation serves as a predictor of organizational commitment, and prevents one's commitment to work.

\section{Research model and hypotheses}

In the light of above explanations, we expect there is a relationship between perceived organizational injustice and organizational commitment. In addition, we propose that two dimensions of work alienation (powerlessness and social isolation) have mediating roles between dimensions of organizational injustice and organizational commitment relationships. We presented the hypotheses and proposed model below.

Hypothesis 1: Employees' perceptions of distributive injustice will be positively associated with their sense of work alienation. Specifically, employees' perceptions of distributive injustice will be associated with their sense of (a) powerlessness, and (b) social isolation. 
Hypothesis 2: Employees' perceptions of procedural injustice will be positively associated with their sense of work alienation. Specifically, employees' perceptions of procedural injustice will be associated with their sense of (a) powerlessness, and (b) social isolation.

Hypothesis 3: Employees' perceptions of distributive injustice will be negatively associated with organizational commitment.

Hypothesis 4: Employees' perceptions of procedural injustice will be negatively associated with organizational commitment.

Hypothesis 5: Work alienation will mediate the relationship between perceived distributive injustice and organizational commitment. Specifically, (a) powerlessness and (b) social isolation will mediate the relationship between perceived distributive injustice and organizational commitment.

Hypothesis 6: Work alienation will mediate the relationship between perceived procedural injustice and organizational commitment. Specifically, (a) powerlessness and (b) social isolation will mediate the relationship between perceived procedural injustice and organizational commitment.

(Insert Figure 1 here)

\section{Methodology}

\subsection{Sample}

Questionnaires were created on the basis of scales obtained from literature, and distributed 700 doctors and nurses working in public and private hospitals in Istanbul via electronic mail and face to face interviews. Of the 700 distributed, 413 questionnaires returned. 30 questionnaires were excluded from the analysis because of the missing or incorrect marking. Finaly, valid 383 questionnaires were analysed. Of the respondents, 66.8 per cent were from public hospitals, and 33.2 per cent were from private hospitals. In terms of profession, 69.8 per cent of the sample consisted of doctors with the remaining 30.2 per cent being nurses.

\subsection{Measures}

All construct items were assessed using a five-point Likert-type scale ranging from $1=$ strongly disagree, and $5=$ strongly agree.

Distributive injustice was assessed with a 4-item scale which measured the perceived injustice related to outcomes such as pay or promotion employees received from organization. Sample item was 'My outcomes doesn't reflect the effort I have put into my work'. Procedural injustice was assessed with a 8-item scale which referred to the procedures used to arrive at outcomes. A sample item included 'I am not able to express my views and feelings during those procedures'. Colquitt's (2001) original scale items converted to negative statements in order to measure the degree of perceived distributive injustice and procedural injustice.

Work Alienation was measured by total 15 -items from two distinct study. Six-items from Leiter (1985) and nine-items used by Yang, Yang, and Kawachi (2001) were adopted to this study. Four of the 15 items for the work alienation scale were dropped because of the weak factor loadings. Work alienation scale included dimensions of powerlessness, and social isolation. Powerlessness was measured by 4 items. A sample item included 'I am not allowed to express my own opinions and views on the job'. The measure of social isolation included 7 items. A sample item was 'I am not able to get practical help from colleagues when difficulties were encountered'.

Organizational commitment was measured by a 5 -item scale adopted from Allen and Meyer (1990). Sample item was 'I really feel as if this organization's problems are my own'.

\subsection{Analysis and results}

We conducted the principal components analysis with a varimax rotation to investigate whether the variables were distinct constructs. In order to conclude whether the amount of data was sufficient to measure our research and adequate for the factor analysis, it was conducted 'Kaiser-Meyer-Olkin (KMO) test' and 'Bartlett's Test of Sphericity'. To be able to perform a factor analysis it must be correlation between variables to a certain extent. If the result of Barlett's test is lower than .05, there is a sufficient relationship between variables to conduct a factor analysis. KMO measure of sampling adequacy varies between 0 and 1 , the minimum acceptable level is .50 , and the result is to be considered better as this value approaches to 1 (Sipahi, Yurtkoru, \& Cinko, 2008).

The results of Barlett's test of our study was .000 (significant at the level of $\mathrm{p}<.001$ ), and KMO result were .920 for organizational injustice dimensions, .875 for work alienation dimensions, and .881 for organizational commitment. Therefore, result of this test indicated that our scale was sufficient to measure the variables. As 
expected, each of the study variables. Table 1 shows descriptive statistics, reliabilities, and pearson correlations for all variables. Croanbach alpha reliabilities for all scales shown on the diagonal in parantheses were above .70, and were acceptable levels. We have proved that the scales we used for our research were all reliable.

(Insert Table 1 here)

After proving that the scales were reliable and sufficient to measure our data, we may search for the correlation analysis. As shown in Table 1, distributive injustice and procedural injustice was positively related with work alienation dimensions and organizational commitment. Distributive injustice was positively correlated with powerlessness $(\mathrm{r}=.271)$, and social isolation $(\mathrm{r}=.267)$ at the level .01 . Procedural injustice was also significantly and positively associated with powerlessness $(\mathrm{r}=.480)$, and social isolation $(\mathrm{r}=.472)$ at the level .01 . The more employees' perceived distributive injustice and procedural injustice the greater they alienate to the work. These results show that employees' levels of perceived distributive injustice and procedural injustice are separately significant predictors of work alienation. But the relationship between procedural injustice and dimensions of work alienation was stronger than the distributive injustice and work alienation relationship.

Distributive injustice and organizational commitment relationship $(\mathrm{r}=-.245)$ was negatively significant $(\mathrm{p}<.01)$. Procedural injustice and organizational commitment relationship $(\mathrm{r}=-.386)$ was also negatively significant at the level .01. The relationships between powerlessness and organizational commitment, and social isolation and organizational commitment were also statistically and negatively significant $(r=-.356, r=-.429$ at the level .01 , respectively).

To test hypotheses 1, 2, 3, and 4, we conducted a series of regression analyses. As shown in Table 2, distributive injustice predicted work alienation dimensions (powerlessness; $\beta=.271$, social isolation; $\beta=.267$ ) and organizational commitment $(\beta=-.245)$ at the level .001 . Procedural injustice was also a significant predictor of powerlessness feeling $(\beta=.480, \mathrm{p}<.001)$ and sense of social isolation $(\beta=.472, \mathrm{p}<.001)$, and organizational commitment $(\beta=-.386, \mathrm{p}<.001)$. Hypothesis $1,2,3$, and 4 were supported. The effects of distributive injustice on work alienation dimensions and organizational commitment were weak relative those of the procedural injustice.

\section{(Insert Table 2 here)}

In hypotheses Hipotez 5 and 6 , it was proposed that work alienation would mediate the relationship betweeen distributive injustice and organizational commitment, and procedural injustice and organizational commitment. To test this relationship, mediated regression analysis was conducted. According to Baron and Kenny (1986) four conditions must be met for a mediation. First, the independent variable must be related to the mediator. This relationship was tested in Table 1 and 2, and found to exist. Distributive injustice and procedural injustice affected both powerlessness and social isolation separately. Second, the independent variable must be related to the dependent variable. This result is also displayed in Table 1 and 2. Distributive injustice and procedural injustice were associated with each of the work alienation dimensions separately. For condition 3 , the mediator must be related to the dependent variable. As shown in Table 1, there were relationships between each of the mediator variables (powerlessness and social isolation) and organizational commitment. For condition 4, the previously significant relationship between the independent variable and the dependent variable must be no longer significant when the mediator is controlled. The independent variable must account for less or no variance when the mediator is included in the regression equation. If the independent variable has no significant effect after controlling for the mediator, full or perfect mediation is supported. If the effect of the independent variable is reduced but still significant when the mediator is controlled, partial mediation is indicated. The results of mediated regression analysis were shown in Table 3.

As shown in Table 3, the previously significant relationship between distributive injustice and organizational commitment $(\beta=-.245, p<.001)$ reduced but was still significant $(\beta=-.161, p<.01)$ when powerlessness was entered as a mediator in regression equation. This result showed that sense of powerlessness partially mediated the relationship between distributive injustice and organizational commitment. Hypothesis 5 a was partially supported. Social isolation also emerged as a partial mediator between distributive injustice and organizational commitment relationship. When social isolation was entered in regression equation the previously significant relationship between distributive injustice and organizational commitment $(\beta=-.245, p<.001)$ reduced but was still significant $(\beta=-.141, \mathrm{p}<.01)$. This result showed that sense of social isolation partially mediated the relationship between distributive injustice and organizational commitment. Hypothesis $5 b$ was partially supported.

(Insert Table 3 here) 
As for the procedural injustice and organizational commitment relationship, which was significant at the level .001 $(\beta=-.391)$, powerlessness had a partial mediating effect. When powerlessness was entered in regression model the effect of procedural injustice on organizational commitment decreased but remained significant $(\beta=-.280, \mathrm{p}<.001)$. Hypothesis 6 a was partially supported. Social isolation also had a mediating effect between procedural injustice and organizational commitment relationship. When social isolation was entered as a mediator in regression equation the previously significant relationship between procedural injustice and organizational commitment $(\beta=-.386, \mathrm{p}<.001)$ reduced but was still significant $(\beta=-.237, \mathrm{p}<.01)$. Hypothesis $6 b$ was partially supported. This results showed that each of the work alienation dimensions partially mediated the relationship between procedural injustice and organizational commitment.

\section{Discussion and conclusion}

The study examined the potential mediating effects of work alienation dimensions on the relationship between organizational injustice and organizational commitment. Results revealed partial support for our hypotheses that dimensions of work alienation partially mediated the relationship between organizational injustice and organizational commitment. The relationship between distributive and procedural injustice and organizational commitment were partially mediated by feelings of powerlessness and social isolation.

Distributive injustice had an effect on powerlessness, and social isolation. But, these relationships were relatively weak. Perceived distributive injustice encourages people to overview whether the procedure used to determine the result is fair. When employees experienced an injustice related to the distribution of resources, firstly they examine whether this allocation decision is fair. If this process is unfair they may show negative reactions (Greenberg, 2004). As a result, distributive injustice is not the most effective form of injustice causing powerlessness, and isolation feelings.

The relationship between procedural injustice and each of the work alienation dimensions were relatively stronger. Powerlessness dimension of work alienation indicates similar views with the control model of procedural justice. An employee who experiences feelings of powerlessness thinks that he/she has not an effect in determining how the resources are distributed. When employees have not the possibility to control decision making process they will not be able to affect decisions, in turn outcomes, and will feel themselves powerless. An organizational environment in which each employee is not equally rewarded and resources are not distributed in a fair manner cause to the feeling of social isolation. In addition, an employee whose concerns, views, needs, and opinions are not considered in a decision making process feel him/her-self isolated. According to group-value model, an unfair procedure indicates that individual is a low status member within the group, and unfairness in this group leads to sense of isolation. This sense of powerlessness and isolation ultimately cause to decrease employees' commitment to the organization.

Results of this study are particulary important in organizations with professional or technical-skilled employees and highlights the previous findings of several researchers. One of the possible consequences of a decrease in organizational commitment is turnover. As Dailey and Kirk (1992) stated loosing successful and highly technical skilled employees may have negative consequences for an organization. Turnover is likely to cause new and additional costs such as the costs of hiring and training of new staff. According to Fang (2001) nurse turnover causes to high administration costs, interrupts hospital functioning and decreases service quality. Organizational commitment was a significant predictor of turnover intention and an effective solution in reducing the turnover rate among nurses. Furthermore, doctors and nurses comprise of the majority of a hospital's staff and they have high training costs (Ding \& Lin, 2006). As Martin and Bennett (1996) stated managers can obtain a committed workforce though creation and maintenance of a procedurally fair organizational climate. The economic costs of procedurally fair treatment are minimal relative to the distributive justice.

The results indicate that hospital managers must pay attention to employees' perceptions of procedural injustice. Employees who perceive that procedures are fair will be more likely to have a sense of control and lower social isolation feelings. These results support the importance of employee participation and control in decision-making processes. Managers should allow employees' to provide information to the decision maker before a decision is made (Posthuma, Maertz, \& Dworkin, 2007). Beecroft, Dorey, and Wenten (2008) also stated that allowing nurses to participate in decision-making, providing them autonomous and empowered behavior, communication, collaboration and openness in relations with other employees increased job satisfaction, improved the quality of care, and facilitated the recruitment and retention. As Siu (2002) stated nurse managers should maintain good social relations with staff, support them and facilitate effective communication at work to improve job satisfaction and reduce subordinates' absent days. As a result their loyalty to the hospital may increase. 
Empowerment may be effective to overcome the sense of powerlessness. According to Kanungo (1992) empowerment is a dealienating strategy in feelings of powerlessness among subordinates. Brashear, Manolis, and Brooks (2005) also stated that empowerment and control allows employees to be more certain of the relationship between their efforts (inputs) and outcomes such as pay or promotion. As Beecroft, Dorey, and Wenten (2008) stated empowerment is likely to cause increased job satisfaction and organizational commitment, and empowered individuals are likely to feel more control over their work. In this respect, future studies should be conducted to find out organizational injustice, work alienation, commitment, and empowerment relationships. As a result of the doctors and nurses heavy work load, we were unable to collect a large number of surveys. Therefore, future study should be conducted on another work environments and/or professions.

\section{References}

Alder, G. S., \& Ambrose, M. L. (2005). Towards understanding fairness judgments associated with computer performance monitoring: An integration of the feedback, justice, and monitoring research. Human Resource Management Review, 15, 43-67.

Allen, B. H., \& LaFollette, W. R. (1977). Perceived Organizational Structure and Alienation Among Management Trainees. Academy of Management Journal, 20(2), 234-341.

Allen, N., \& Meyer, J. (1990). The measurement and antecedents of affective, continuance, and normative commitment to the organization. Journal of Occupational Psychology, 63, 1-17.

Ambrose, M. L., Seabright, M. A., \& Schminke, M. (2002). Sabotage in the workplace: The role of organizational injustice. Organizational Behavior and Human Decision Processes, 89, 947-965.

Armstrong-Stassen, M. (2006). Determinants of How Managers Cope with Organisational Downsizing. Applied Psychology: An International Review, 55(1), 1-26.

Aryee, S., Budhwar, P. S., \& Chen, Z. X. (2002). Trust as a mediator of the relationship between organizational justice and work outcomes: test of a social exchange model. Journal of Organizational Behavior, 23, 267-285.

Bacharach, S. B., \& Aiken, M. (1979). The Impact of Alienation, Meaninglessness, and Meritocracy on Supervisor and Subordinate Satisfaction. Social Forces, 57, 853-870.

Banai, M., \& Reisel, W. D. (2007). The influence of supportive leadership and job characteristics on work alienation: A six-country investigation. Journal of World Business, 42, 463-476.

Banai, M., Reisel, W. D., \& Probst, T. M. (2004). A managerial and personal control model: perceptions of work alienation and organizational commitment in Hungary. Journal of International Management, 10, 375-392.

Baron, R. M., \& Kenny D. A. (1986). The moderator-mediator variable distinction in social psychological research: Conceptual strategic and statistical considerations. Journal of Personality and Social Psychology, 51, 1173-1182.

Beecroft, P. C., Dorey, F., \& Wenten, M. (2008). Turnover intention in new graduate nurses: a multivariate analysis. Journal of Advanced Nursing, 62(1), 41-52.

Berger, L. K., Sedivy, S. K., Cisler, R. A., \& Dilley, L. J. (2008). Does Job Satisfaction Mediate the Relationships Between Work Environment Stressors and Employee Problem Drinking?. Journal of Workplace Behavioral Health, 23(3), 229-244.

Boer, E. M. D., Bakker, A. B., Syroit, J. E., \& Schaufeli, W. B. (2002). Unfairness at work as a predictor of absenteeism. Journal of Organizational Behavior, 23, 181-197.

Brashear, T. G., Manolis, C., \& Brooks, C. M. (2005). The effects of control, trust, and justice on salesperson turnover. Journal of Business Research, 58, 241- 249.

Brooks, A., \& Zeitz, G. (1999). The Effects of Total Quafity Management and Perceived Justice on Organizational Commitment of Hospital Nursing Staff. Journal of Quality Management, 4(1), 69-93.

Byrne, Z. S. (2005). Fairness reduces the negative effects of organizational politics on turnover intentions, citizenship behavior and job performance. Journal of Business and Psychology, 20(2), 175-200.

Cohen-Charash, Y., \& Spector, P. (2001). The role of justice in organizations: A meta-analysis. Organizational Behavior and Human Decision Processes, 86, 278-232.

Colquitt, J.A. (2001). On the dimensionality of organizational justice: A construct validation of a measure. Journal of Applied Psychology, 86: 386-400. 
Colquitt, J. A., Conlon, D. E., Wesson, M. J., Porter, C. O. L. H., \& Yee NG, K. (2001). Justice at the Millennium: A Meta-Analytic Review of 25 Years of Organizational Justice Research. Journal of Applied Psychology, 86(3), 425-445.

Colquitt, J. A., Scott, B. A., Judge, T. A., \& Shaw, J. C. (2006). Justice and personality: Using integrative theories to derive moderators of justice effects. Organizational Behavior and Human Decision Process, 100, $110-127$.

Cropanzano, R., Byrne, Z. S., Bobocel, D. R., \& Rupp, D. E. (2001). Moral Virtues, Fairness Heuristics, Social Entities, and Other Denizens of Organizational Justice. Journal of Vocational Behavior, 58, 164-209.

Dailey, R. C., \& Kirk, D. J. (1992). Distributive and Procedural Justice as Antecedents of Job Dissatisfaction and Intent to Turnover. Human Relations, 45, 305-317.

DeConinck, J., \& Bachmann, D. (2005). An analysis of turnover among retail buyers. Journal of Business Research, 58, 874-882.

Ding, C. G., \& Lin, C. P. (2006). Comparing the Effects of Determinants of Turnover Intentions Between Taiwanese and U.S. Hospital Employees. Human Resource Development Quarterly, 17(4), 403-421.

Elovainio, M., Kivimaki, M., Steen, N., \& Vahtera, J. (2004). Job decision latitude, organizational justice and health: multilevel covariance structure analysis. Social Science and Medicine, 58, 1659-1669.

Elovainio, M., Van den Bos, K., Linna, A., Kivimaki, M., Ala-Mursula, L., Pentti, J., \& Vahtera, J. (2005). Combined effects of uncertainty and organizational justice on employee health: Testing the uncertainty management model of fairness judgments among Finnish public sector employees. Social Science and Medicine, 61(12), 2501-2512.

Enshner, E. A., Grant-Vallone, E. J., \& Donaldson, S. I. (2001). Effects of Perceived Discrimination on Job Satisfaction, Organizational Commitment, Organizational Citizenship Behavior, and Grievances. Human Resource Development Quarterly, 12(1), 53-72.

Fang, Y. (2001). Turnover propensity and its causes among Singapore nurses, an empirical study. International Journal of Human Resource Management, 12(5), 859-871.

Folger, R., \& Konovsky, M. A. (1989). Effects of Procedural and Distributive Justice on Reactions to Pay Raise Decisions. Academy of Management Journal, 32(1), 115-130.

Gilbert, J. A., \& Ivanchevich, J. M. (1999). A Re-examination of Organizational Commitment. Journal of Social Behavior and Personality, 14(3), 385-396.

Greenberg, J. (1990). Organizational Justice: Yesterday, Today and tomorrow. Journal of Management, 16, 399-432.

Greenberg, J. (2001). Setting the Justice Agenda: Seven Unanswered Questions about What, Why, and How. Journal of Vocational Behavior, 58, 210-219.

Greenberg, J. (2004). Stress Fairness to Fare No Stress: Managing Workplace Stress by Promoting Organizational Justice. Organizational Dynamics, 33(4), 352-365.

Greenberg, J. (2006). Losing Sleep Over Organizational Injustice: Attenuating Insomniac Reactions to Underpayment Inequity With Supervisory Training in Interactional Justice. Journal of Applied Psychology, 91(1), 58-69.

Greenberg, J., \& Barling, J. (1999). Predicting employee aggression against coworkers, subordinates and supervisors: the roles of person behaviors and perceived workplace factors. Journal of Organizational Behavior, 20, 897-913.

Hegtvedt, K. A., Clay-Warner, J., \& Johnson, C. (2003). The Social Context of Responses to Injustice: Considering the Indirect and Direct Effects of Group-Level Factors. Social Justice Research, 16(4), 343-367.

Hirschfeld, R. R., \& Feild, H. S. (2000). Work centrality and work alienation: distinct aspects of a general commitment to work. Journal of Organizational Behavior, 21, 789-800.

Hubbel, A. P., \& Chory-Assad, R. M. (2005). Motivating Factors: Perceptions of Justice and Their Relationship with Managerial and Organizational Trust. Communication Studies, 56(1), 47-70.

Judge, T. A., \& Colquitt, J. A. (2004). Organizational Justice and Stress: The Mediating Role of Work-Family Conflict. Journal of Applied Psychology, 89(3), 395-404. 
Kanungo, R. N. (1983). Work Alienation: A Pancultural Perspective. International Studies of Management and Organization, 13, 119-138.

Kanungo, R. N. (1992). Alienation \& Empowerment: Some Ethical Imperatives in Business. Journal of Business Ethics, 11, 413-422.

Konovsky, M. A. (2000). Understanding Procedural Justice and Its Impact on Business Organizations. Journal of Management, 26, 489-511.

Lambert, E. G., Hogan, N. L., \& Griffin, M. L. (2007). The impact of distributive and procedural justice on correctional staff job stress, job satisfaction, and organizational commitment. Journal of Criminal Justice, 35, 644-656.

Leiter, J. (1985). Work Alienation in the Textile Industry: Reassessing Blauner. Work and Occupations, 12, 479-498.

Leiter, M.P., \& Maslach, C. (2009). Nurse turnover: the mediating role of burnout. Journal of Nursing Management, 17, 331-339.

Martin, C. L., \& Bennett, N. (1996). The role of justice judgments in explaining the relationship between job satisfaction and organizational commitment. Group and Organization Management, 21(1), 84-104.

Mendoza, M. J. S., \& Lara, P. Z. M. (2007). The impact of work alienation on organizational citizenship behavior in the Canary Islands. International Journal of Organizational Analysis, 15(1), 56-76.

Miller, J. (1975). Isolation in Organizations: Alienation from Authority, Control, and Expressive Relations. Administrative Science Quarterly, 20, 260-271.

Mulki, J. P., Locander, W. B., Marshall, G. W., Harris, E. G., \& Hensel, J. (2008). Workplace isolation, salesperson commitment, and job performance. Journal of Personal Selling and Sales Management, 28(1), 67-78.

Nasurdin, A. M., Ramayah, T., \& Kumaresan, S. (2005). Organizational Stressors and Job Stress among Managers: The Moderating Role of Neuroticism. Singapore Management Review, 27, 63-79.

Posthuma, R. A., Maertz, C. P., \& Dworkin, J. B. (2007). Procedural justice's relationship with turnover: Explaining past inconsistent findings. Journal of Organizational Behavior, 28, 381-398.

Price, K. H., Lavelle, J. J., Henley, A. B., Cocchiara, F. K., \& Buchanan, F. R. (2006). Judging the fairness of voice-based participation across multiple and interrelated stages of decision making. Organizational Behavior and Human Decision Processes, 99, 212-226.

Ramamoorthy, N., \& Flood, P. C. (2004). Gender and Employee Attitudes: The Role of Organizational Justice Perceptions. British Journal of Management, 15, 247-258.

Robbins, T. L., Summers, T. P., \& Miller, J. L. (2000). Intra- and inter-justice relationships: Assessing the direction. Human Relations, 53(10), 1329-1355.

Sarros, J. C., Tanewski, G. A., Winter, R. P., Santora, J. C., \& Densten, I. L. (2002). Work Alienation and Organizational Leadership. British Journal of Management, 13, 285-304.

Schmitt, M., \& Dörfel, M. (1999). Procedural injustice at work, justice sensitivity, job satisfaction and psychosomatic well-being. European Journal of Social Psychology, 29, 443-453.

Shepard, J. M. (1970). Functional Specialization: Alienation, \& Job Satisfaction. Industrial and Labor Relations Review, 23(2), 207-219.

Sipahi, B., Yurtkoru, E. S., \& Cinko, M. (2008). Sosyal Bilimlerde SPSS'le Veri Analizi, 2nd ed., Istanbul, (Chapter 4), ISBN: 978-975-295-827-2.

Siu, O. (2002). Predictors of job satisfaction and absenteeism in two samples of Hong Kong nurses. Journal of Advanced Nursing, 40, 218-229.

Sweeney, P. D., \& McFarlin, D. B. (1997). Process and outcome: gender differences in the assessment of justice. Journal of Organizational Behavior, 18, 83-98.

Tabak, N., \& Koprak, O. (2007). Relationship between how nurses resolve their conflicts with doctors, their stress and job satisfaction. Journal of Nursing Management, 15, 321-331.

Tallman, R., Phipps, K., \& Matheson, D. (2009). Justice perception in Medical Administrative Governance. International Journal of Business Research, 9(7), 147-155. 
Tata, J. (2000). Influence of Role \& Gender on the Use of Distributive Versus Procedural Justice Principles. The Journal of Psychology, 134, 261-268.

Taylor, S., White, B., \& Muncer, S. (1999). Nurses' cognitive structural models of work-based stress. Journal of Advanced Nursing, 29(4), 974-983.

VanYperen, N. W., Hagedoorn, M., Zweers, M. \& Postma, S. (2000). Injustice and Employees' Destructive Responses: The Mediating Role of State Negative Affect. Social Justice Research, 13(3), 291-312.

Vermunt, R., \& Steensma, H. (2003). Physiological Relaxation: Stress Reduction Through Fair Treatment. Social Justice Research, 16(2), 135-149.

Yang, M. J., Yang, M. S., \& Kawachi, I. (2001). Work experience and drinking behavior: alienation, occupational status, workplace drinking subculture and problem drinking. Public Health, 115, 265-271.

Zellars, K. L., Liu, Y., Bratton, V., Brymer, R., \& Perrewe, P. L. (2004). An Examination of the Dysfunctional Consequences of Organizational Injustice and Escapist Coping. Journal of Managerial Issues, 16(4), 528-545.

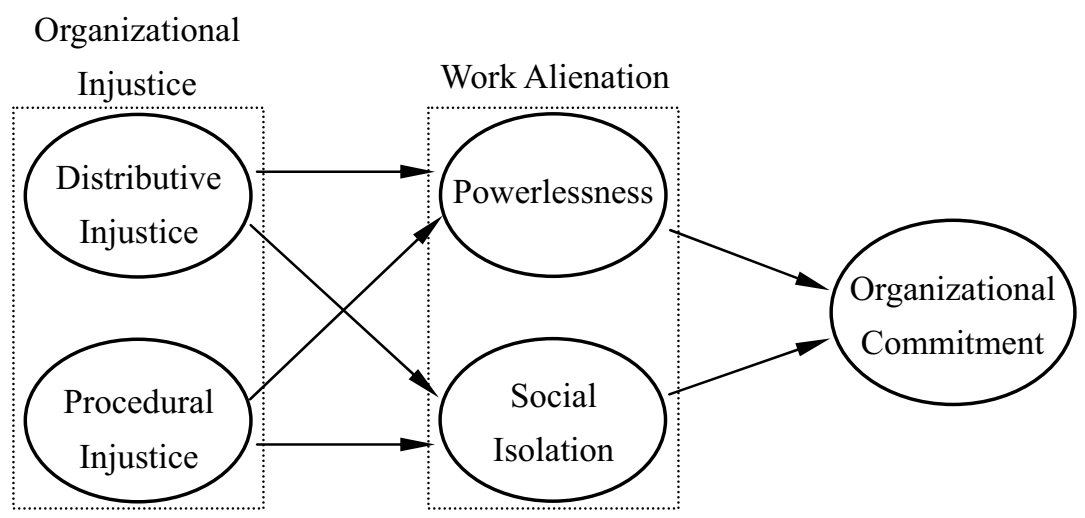

Figure 1. Proposed Model

The Figure describes the mediating role of work alienation between organizational injustice and organizational commitment relationship

Table 1. Results of Correlation Analysis $(N=383)$

\begin{tabular}{|lccccccc|}
\hline & Mean & \multicolumn{1}{c}{ SD } & $\mathbf{1}$ & $\mathbf{2}$ & $\mathbf{3}$ & $\mathbf{4}$ & $\mathbf{5}$ \\
\hline 1. Distributive Injustice & 3.7689 & 1.0660 & $(.91)$ & & & & \\
2. Procedural Injustice & 3.2935 & .9969 & $.581^{* *}$ & $(.92)$ & & & \\
3. Powerlessness & 2.6390 & .9370 & $.271^{* *}$ & $.480^{* *}$ & $(.84)$ & & \\
4. Social Isolation & 2.7203 & .9191 & $.267^{* *}$ & $.472^{* *}$ & $.542^{* *}$ & $(.90)$ & \\
5. Organizational Commitment & 2.9843 & 1.0317 & $-.245^{* *}$ & $-.386^{* *}$ & $-.356^{* *}$ & $-.429^{* *}$ & $(.91)$ \\
\hline
\end{tabular}

${ }^{* *} p<.01$, All significance tests are two-tailed.

Croanbach alpha reliabilities for all scales shown on the diagonal in parantheses

Table shows descriptive statistics, reliabilities, and pearson correlations for all variables 
Table 2. Regression Analys is Results for Hypotheses 1-4

\begin{tabular}{|c|c|c|c|c|c|c|c|c|}
\hline \multirow[b]{2}{*}{ Variable } & \multicolumn{2}{|c|}{ Powerlessness } & \multicolumn{3}{|c|}{ Social Is olation } & \multicolumn{3}{|c|}{ Organiza.Commitment } \\
\hline & $\boldsymbol{\beta}$ & $p$ & $\boldsymbol{\beta}$ & $t$ & $p$ & $\beta$ & $t$ & $p$ \\
\hline \multirow[t]{3}{*}{ Dis tributive Injustice } & $.271^{* * *} 5.493$ & .000 & $.267^{* * *}$ & 5.406 & .000 & $-.245^{* * *}$ & -4.941 & .000 \\
\hline & \multicolumn{2}{|l|}{$R^{2}=.073$} & \multicolumn{3}{|c|}{$R^{2}=.071$} & \multicolumn{3}{|c|}{$R^{2}=.060$} \\
\hline & \multicolumn{2}{|c|}{$F=30.177^{* * *}$} & \multicolumn{3}{|c|}{$F=29.222^{* * *}$} & \multicolumn{3}{|c|}{$F=24.410^{* * *}$} \\
\hline \multirow[t]{3}{*}{ Procedural Injustice } & $.480^{* * *} 10.692$ & .000 & $.472^{* * *}$ & 10.444 & .000 & $-.386^{* * *}$ & -8.175 & .000 \\
\hline & \multicolumn{2}{|l|}{$R^{2}=.231$} & \multicolumn{3}{|c|}{$R^{2}=.223$} & \multicolumn{3}{|c|}{$R^{2}=.149$} \\
\hline & \multicolumn{2}{|c|}{$F=114.322^{* * *}$} & \multicolumn{3}{|c|}{$F=109.070^{* * *}$} & \multicolumn{3}{|c|}{$F=66.826^{* * *}$} \\
\hline
\end{tabular}

${ }^{* *} p<.001$, All significance tests are two-tailed

The table shows the explained variances, significances, and coefficients for mediator and dependent variables

Table 3. Hierarchical Regression Results for Hypotheses 5 and 6

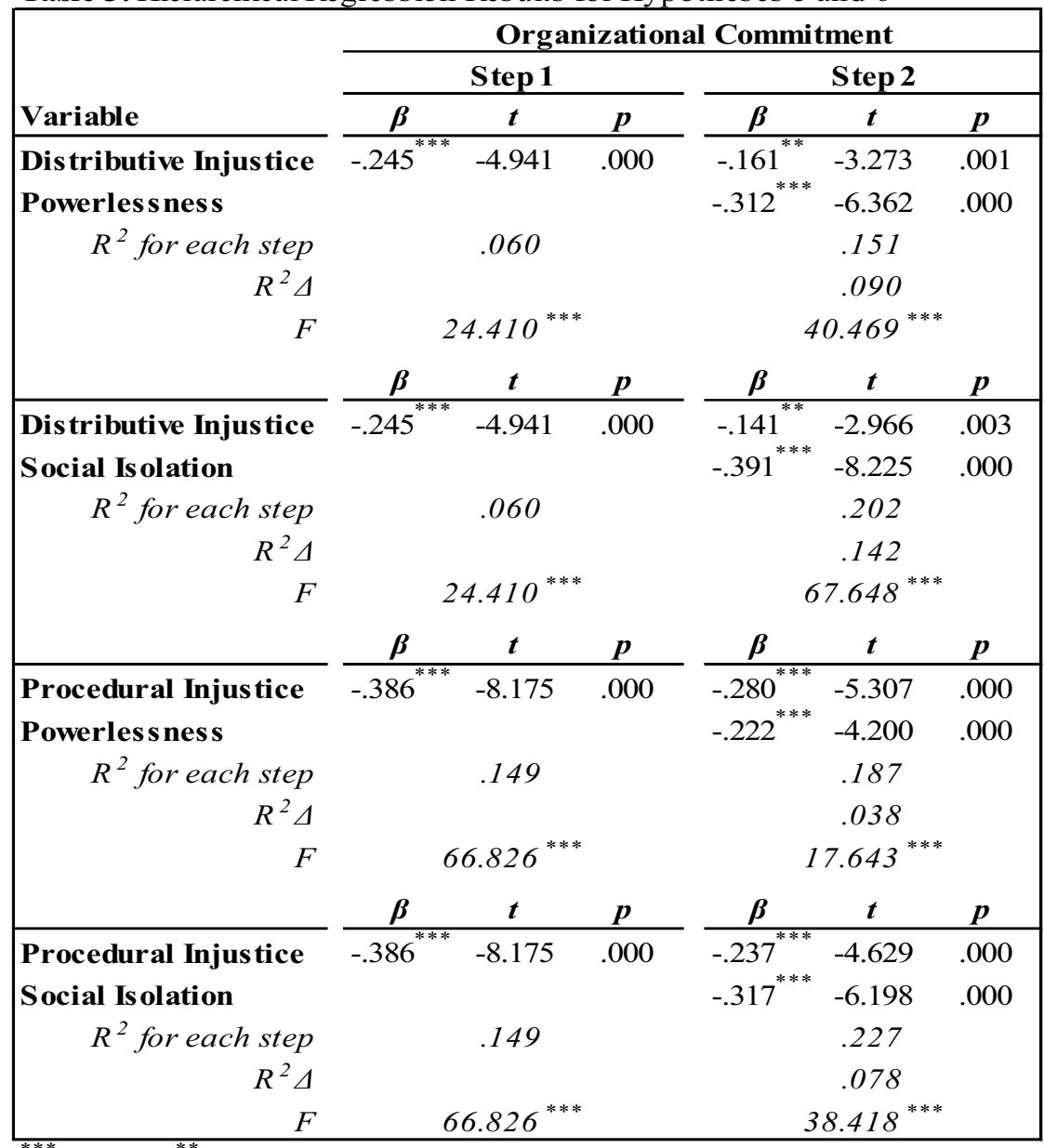

$p<.001,{ }^{* *} p<.01$ All significance tests are two-tailed.

Table shows explained variances, coefficients, significances at each step 